\title{
Representasi Identitas Muslimah Modern "Jilbab Traveler" dalam Novel Karya Asma Nadia
}

\author{
Rani Dwi Putri ${ }^{1 *}$ \\ ${ }^{1}$ Departemen Sosiologi, Universitas Gadjah Mada, Yogyakarta - Indonesia
}

\begin{abstract}
Following the fall of the New Order era, which encouraged media development and openness, Islam was positioned as a dominant identity in public spaces. Asma Nadia is one of the actors who is become one part of those phenomena. Her works in novels, films and soap operas have succeeded in combining modern elements with Islamic symbols and values. The theme of "jilbab traveler" is one example. Applying text analysis focusing on three works of Asma Nadia's novels, namely The Jilbab Traveler; Assalamualaikum Beijing; Jilbab Traveler: Love Sparks in Korea, this article reveals that Asma Nadia illustrates "jilbab traveler" as both agile and pious. The ambition to travel around the world accompanied by its inherent attributes represents the figure of "jilbab traveler" as an agile woman, while hijab (veil) presents an image of a pious woman. On the other side, the wearing of the veil becomes a distinction and provides such negotiation space and illustrates the hegemonic masculinity of patriarchal culture.
\end{abstract}

Berakhirnya era Orde Baru yang mendorong perkembangan dan keterbukaan media telah membawa Islam sebagai identitas yang mendominasi ruang-ruang publik. Asma Nadia adalah salah satu aktor yang tidak bisa dilepaskan dari fenomena tersebut. Karya-karyanya baik di novel, film, maupun sinetron sukses dalam memadukan unsur-unsur modern dengan simbol dan nilai Islam. Tema "jilbab traveler" menjadi salah satunya. Dengan menggunakan analisis teks yang berfokus pada tiga karya novel dari Asma Nadia: The Jilbab Traveler; Assalamualaikum Beijing; Jilbab Traveler: Love Sparks in Korea, penelitian ini mengungkapkan bahwa Asma Nadia menggambarkan "jilbab traveler" sebagai sosok yang lincah dan shalihah. Ambisi untuk keliling dunia serta atribut yang menyertainya membawa sosok "jilbab traveler" pada penggambaran perempuan yang lincah, sedangkan jilbab memberikan kesan shalihah. Di sisi yang lain penggunaan jilbab tidak hanya menjadi pembeda dan menyediakan ruang negosiasi, tetapi juga menggambarkan hegomoni maskulinitas dari budaya patriarki.

Keywords: jilbab traveler; modern female Muslim; Asma Nadia; Islam popular

*Korespondensi Penulis: Rani Dwi Putri (ranidwiputri@ugm.ac.id), Jl. Sosio Yustisia No.1, Bulaksumur, Yogyakarta 55281, Indonesia. 


\section{Pendahuluan}

Sepanjang tahun 1980an sulit menemukan Islam yang berasosiasi dengan pelbagai icon modernitas, gaya hidup perkotaan, maupun budaya populer. Heryanto (2011) mengungkapkan bahwa keadaan tersebut sepenuhnya berubah sejak dua dekade terakhir di mana Islam berada di garis terdepan dalam memproduksi dan mengonsumsi budaya populer. Heryanto (2015) memberi gambaran di film Ayat-Ayat Cinta yang laris manis di tahun 2008 dan mampu memenangkan hati kelas menengah perkotaan. Film bergenre Islam kontemporer dengan perpaduan budaya barat (westernoriented) dan budaya populer ini mampu merepresentasikan kaum Muslim muda zaman sekarang yang berusaha untuk berpartisipasi secara penuh di dunia modern tanpa melepaskan keimanan mereka (Heryanto (2015).

Dalam studinya yang mengambil kasus Bangladesh, Huq (1999) mengungkapkan bahwa dalam konteks sekarang wacana Islam tidak hanya terasosiasi dengan Madrasah atau pendidikan Islam, namun lebih luas lagi. Islam kini muncul pada ruang dan media publik, dan salah satunya adalah media sastra. Tren ini memungkinkan untuk mengaburkan batas-batas di antara "religious" dan "secular" - yang selama ini dianggap berlawanan. Huq (1999) secara khusus mengambil kasus perubahan tren budaya literatur di Bangladesh khususnya novel untuk menjelaskan fenomena tersebut. Menariknya adalah bahwa novel menghadirkan imajinasi kreatif para pembacanya. Perpaduan antara alur cerita romantis (yang secara jelas digolongkan pada literatur sekuler) dan budaya islami mampu menembus batas-batas imajinasi budaya di antara kedua ideologi tersebut. Di sisi yang lain, ini juga sebagai upaya menciptakan platform untuk kritik Islamis terhadap ideologi dan praktik sekuler (Huq 1999).

Dalam konteks Indonesia, nama Asma Nadia menjadi salah satu novelis islami dengan karya yang mencapai 53 buah baik dalam bentuk novel, buku, maupun cerita pendek -dan tentu dengan ratusan pembaca setia (antusiasme pembaca salah satunya tercermin dalam web membaca online secara gratis pada laman www. goodreads.com). Selain itu, Asma Nadia juga aktif melakukan ekspansi cerita-cerita novelnya ke bentuk film maupun sinetron dengan puluhan episode. Hal ini tentu menggambarkan apa yang disebut oleh Gramsci (1971; 1975) sebagai hegemoni -kekuasaan atas suatu budaya yang diperoleh melalui politik kultural- Asma Nadia atas wacana Islam dan budaya populer di Indonesia yang cukup signifikan. Hampir seluruh karyanya mengadopsi cerita-cerita kaum muda yang khas di zaman modern, namun juga tetap pada koridor keislaman. Dalam karyakaryanya, Asma mencoba untuk menggambarkan hiruk-pikuk permasalahan dan gaya hidup remaja mulai dari persahabatan, perjuangan dan mimpi keliling dunia, pengkhianatan, hingga percintaan ala kaum muda kontemporer. Cerita dengan tema-tema ini memang mampu memberikan percikan problematika yang khas. Nuansa islami membalut setiap teks dan alur cerita yang dibangun oleh Asma Nadia dalam karyanya. Benturan antara gagasan kehidupan anak muda modern yang syarat akan gejolak kebebasan dalam rangka pencarian jati diri dan dinamika transisinya menuju dewasa (Nilan dan Mansfield 2013) dengan gagasan islami yang 
mencerminkan sebuah batasan, menunjukkan bagaimana Asma Nadia mencoba membangun ruang negosiasi.

Dalam studinya, Pamungkas (2015) telah mengidentifikasi penggambaran Muslimah modern pada majalah Ummi pasca-Orde Baru yang menggambarkan pada sosok Muslimah yang tidak hanya shalih tetapi juga mampu menyesuaikan tuntutan zaman. Pamungkas (2015) memberikan tiga karakteristik utama pada sosok "Muslimah modern" yang tergambarkan dalam majalah Ummi. Pertama, modesty and sanctity yaitu Muslimah yang memiliki jiwa humble dan menyenangkan bagi orang lain, juga tetap mempertahankan keyakinan dan kesalehan melalui simbol kerudung (veil). Kedua, sanctity and mobility mencerminkan Muslimah yang aktif di ranah publik tetapi juga tetap menjaga kesuciannya melalui simbol kerudung. Ketiga, beauty and modesty menggambarkan Muslimah yang terlihat menarik dan memukau dengan sedikit aksesoris dan jilbab berwarna tetapi juga tetap terlihat sederhana (sesuai aturan Islam).

Dalam konteks ini Pamungkas (2015) menegaskan bahwa penekanan pada sifat seperti modesty, sanctity, beauty, and mobility tidak hanya sebagai sebuah penggambaran dalam majalah, namun juga mempengaruhi preferensi para pembacanya. Ini alasan mengapa majalah Ummi tidak lagi hanya menjalankan fungsi dakwah, tetapi juga bergeser menjadi alternatif life-style atau budaya konsumsi dimana nilainilai agama menjadi 'major feature'.

Begitu halnya dengan karya Asma Nadia yang mampu memberikan pengambaran sosok "Muslimah modern" melalui konsep Jilbab
Traveler. Setidaknya terdapat tiga karya Asma Nadia yang secara ketara menggambarkan perempuan dengan segala pengalaman cerita traveling-nya. Pertama, The Jilbab Traveler yang diterbitkan pada tahun 2012. Dengan mengusung tagline "berjilbab nggak berarti kamu nggak bisa keliling dunia!", novel ini mengisahkan pengalaman para Muslimah yang mampu berkeling dunia dan tetap bisa mempertahankan jilbabnya sebagai tanda keIslamannya. Kedua, Assalamu-alaikum Beijing yang terbit pada tahun 2013 ini sedikit memberikan nuansa berbeda. Novel ini menampilkan bumbu-bumbu percintaan di mana kegagalan cinta Asmara (tokoh utama) membawanya ke Baijing untuk bekerja. Ketiga, Jilbab Traveler: Love Sparks in Korea yang terbit pada tahun 2015. Novel ini menampilkan sosok Rania, gadis yang dijuluki sang "jilbab traveler" mampu mengukuhkan mimpinya untuk keliling dunia. Bahkan, ia telah menjelajahi 60 negara yang memberikan banyak pengalaman akan keindahan lukisan Sang Maha Pencipta.

Berpijak dari konseptualisasi "muslimah modern" dari Pamungkas (2015), studi ini ditempatkan pada bentuk lain dari representasi Muslimah modern yang dikonstruksikan melalui karya sastra. Di sisi yang lain, studi ini juga berusaha untuk menyediakan narasi alternatif atas wacana perempuan Muslim dalam konteks modernitas dan memotret realitas pada kemunculan simbol-simbol Islam dalam ruangruang publik terutama pada budaya populer.

Penelitian ini menggunakan analisis teks dengan berfokus pada tiga karya Asma Nadia. Hawkins (2018) menjelaskan bahwa analisis teks merupakan metode yang digunakan dalam 
memahami bahasa, simbol dan/atau gambar yang disajikan dalam teks. Piliang (2004) menambahkan bahwa analisis teks berfokus pada proses pengkajian teks sebagai sebuah "produk penggunaan bahasa" berupa kumpulan atau kombinasi- kombinasi tanda. Lebih detailnya, menyangkut sistem tanda (sintatik/paradigmatik), tingkatan tanda (denotasi/ konotasi), relasi antar tanda (metafora metonim), muatan mitos, dan ideologi dibaliknya.

Data yang digunakan dalam studi ini adalah teks dari tiga novel karya Asma Nadia: The Jilbab Traveler; Assalamualaikum Beijing; Jilbab Traveler: Love Sparks in Korea. Setiap teks dalam tiga karya ini akan menjadi data primer dalam studi ini. Lebih spesifik, metode yang digunakan yaitu dengan melihat dan menelaah alur cerita, alur pemikiran, dan tata bahasa penulis. Selain itu, detail cover dan gambar atau tanda yang merepresentasikan tema juga menjadi objek kajian dalam penelitian ini.

\section{Memahami Representasi dan Identitas}

Studi ini menggunakan konsep representasi dan identitas dari Hall (1977) dan Barker (2016) (2016) dalam memahami "jilbab traveler" sebagai bentuk identitas Muslimah modern. Hall (1977: 222) menekankan pada pemahaman bahwa "representation is the production of the meaning of the concepts in our minds through language". Bahasa (language) dalam konteks ini memungkinkan kita untuk menghubungkan antarkonsep yang mengacu pada dunia nyata, benda, orang atau peristiwa, maupun imajinasi fiski. Secara sederhana, bahasa digunakan untuk mengatakan sesuatu yang mewakili kejadian dunia. Bahasa di sini memiliki arti yang luas, tidak hanya dimaknai sebagai tutur kata atau tulisan, namun lebih jauh berbagai tanda dan simbol yang dapat dimaknai dan direpresentasikan sehingga bisa berbentuk gambar, suara, bahkan objek dan peristiwa tertentu (Shafita 2009).

Bahasa juga tidak bisa lepas dari sebuah pemaknaan dimana bahasa merupakan media produksi dan pertukaran makna. Sedangkan proses pemaknaan selalu melibatkan sistem representasi. Representasi memberikan makna kepada dunia dengan membangun satu set korespondensi antara hal-hal yang menyangkut benda, orang, peristiwa, tanda, dan konsep. Oleh karenanya, Hall menyebutkan bahwa jantung dari proses makna dalam budaya adalah "Sistem representasi". At the heart of the meaning process in culture, then, are two related 'systems of representation' (Hall 1977: 19). Dalam hal ini representasi dimaknai sebagai proses merekatkan semua tanda-tanda menjadi makna dan makna sendiri bersifat subjektif, tidak pernah tetap, selalu berubah dan selalu bergerak (Lasman 2010). Proses representasi sendiri tidak bisa dipisahkan dari identitas yang menyangkut diri atau subjek yang men-jadi pencipta sekaligus objek penciptaan dari serangkaian proses pembentukannya. Barker (2016) kemudian menegaskan, identitas sepenuhnya merupakan suatu konstruksi sosial dan tidak mungkin eksis (mengada) di luar representasi kultural dan akulturasi. Menurut Barker terdapat dua pandangan dominan dalam melihat proses pembentukan identitas seseorang. Pertama, identitas politik yang dibentuk melalui posisi subjek dalam suatu kelompok ataupun komunitas. Identitas ini akan mem- 
bentuk rasa kepemilikan (sense of belonging) sekaligus pembeda (sense of different) seseorang terhadap kelompok satu dengan lainnya. Kedua, identitas yang terbentuk melalui penentuan posisi dan proses subjek di dalam relasi maupun interaksi sosialnya, Barker menyebutnya sebagai identitas budaya. Identitas ini lebih bersifat cair dan fleksibel sehingga setiap saat mampu mengalami reproduksi secara terus menerus.

Dalam konteks ini Hall (1977:222) menegaskan bahwa identitas budaya (cultural identity) sebagai sesuatu yang cair dan mudah dibentuk melalui proses representasi.

"Identity is not as transparent or unproblematic as we think. Perhaps instead of thinking of identity as an already accomplished fact, which the new cultural practices then represent, we should think, instead, of identity as a 'production', which is never complete, always in process, and always constituted within, not outside, representation. This view problematises the very authority and authenticity to which the term, 'cultural identity', lays claim."

Setidaknya, Hall menyoroti dua pemikiran berbeda dalam memandang identitas budaya. Pertama, identitas diposisikan dalam budaya yang sama secara kolektif dengan menyembunyikan hal lain secara paksa. Pemikiran ini memandang bahwa identitas budaya kita mencerminkan pengalaman sejarah umum dan kode budaya bersama yang membawa kita pada 'one true self, dengan bingkai yang stabil dan tidak berubah. Identitas seperti ini merupakan identitas yang bersifat esensialisme di mana identitas akan melanjutkan kerangka acuan dan pemak-naan di bawah perubahan sejarah. Model pemikiran ini memang mempunyai peran penting dalam tradisi post-colonialism.

Kedua, identitas budaya yang dibentuk oleh sejarah dan unsur-unsur kebudayaan yang bersifat cair dan mudah berubah sesuai ruang dan waktunya. Model ini mengakui terdapat titik-titik kritis perbedaan mendalam dan signifikan dalam memahami sejarah yang menekankan pada 'what we have become'. Di mana identitas terus menerus bermain ('play') dalam sejarah, budaya, dan kekuasaan. Dalam pemikiran yang kedua ini, Hall menegaskan kembali bahwa identitas budaya adalah persoalan tentang bagaimana seorang membentuk dirinya seperti sebagai becoming and being Angkasa 2012). Model kedua ini merupakan identitas budaya yang bersifat anti-esensialisme.

\section{Islam di Dalam Ruang Publik}

Setelah lebih dari 30 tahun kepemimpinan Presiden Soeharto, ragam identitas seolah "dininabobokkan" di ruang-ruang privat. Pada era ini ragam identitas agama dikontrol melalui program standarisasi dari pendidikan, sosial dan kultur keagamaan dengan menekankan pada promosi yang lebih konservatif terhadap nilainilai Pancasila (Smith-Hefner 2007). Oleh karena itu, keruntuhan Orde Baru seolah menjadi titik awal munculnya ragam identitas di ruang publik Ini bersamaan dengan arus lebih besar dari kebebasan berekpresi dan pertumbuhan kelas menengah perkotaan (Nilan 2013). Selebrasi dan pertunjukkan identitas menjadi sebuah tontonan bersama. Pada tahap yang sama, kemunculan media-media baru seperti saluran televisi swasta, CD audio, film, saluran TV kabel, dan internet mampu menopang kemenangan ini. 
Namun, di akhir masa Orde Baru, tahun 1990an, Presiden Soeharto memberikan ruang istimewa pada kelompok Islam sebagai strategi politiknya (Heryanto 2015). Keputusan ini memberikan dampak yang cukup besar tidak hanya pada kelompok Islam dalam politik pemerintahan, tetapi juga kiprahnya terutama dalam ranah publik. Salah satunya adalah penerapan hukum Syariah di sejumlah provinsi di Indonesia dengan mengenakan hukuman kepada pelajar perempuan yang tidak memakai jilbab (Heryanto 2015). Kemudian, pada tahuntahun berikutnya jilbab dan atribut Islam lainnya terus menguasai ruang-ruang publik dan menjadi praktik umum terutama di antara perempuan kelas menengah perkotaan (Utomo et al 2018) . Bahkan, jilbab menjadi salah satu atribut yang menghiasi berbagai tayangan televisi maupun film Indonesia (Barkin 2014) Dalam konteks ini, Islam tidak hanya dipandang sebagai sebuah objek budaya yaitu "alat" yang dimanfaatkan dalam ragam budaya seperti film, novel, maupun tayangan televisi (Islam dalam ruang publik). Namun, Islam juga berkedudukan sebagai subjek budaya yaitu Islam sebagai budaya itu sendiri. Di mana Islam mampu menghasilkan nilai, norma, dan paham yang menyebar di ruang-ruang publik (Islam di ruang publik).

Anderson dan Eickelman (1999) dalam New Media in the Musim World: The Emerging Public Sphere mendefisinikan gejala tersebut sebagai "Muslim Publics". Dengan melihat negara-negara mayoritas Muslim terutama Mesir, Eickelman dan Anderson menjelaskan bahwa kemunculan Muslim Publics ditandai dengan keterbukaan akses simbol identitas dan juga atas meningkat- nya media baru serta akses komunikasi. Muslim publics sphere exists at the intersection of media in the modern world, political, and social life (Anderson dan Eickelman 1999). Sehingga keadaan ini memicu pada keterbukaan ruang global dimana persaingan dan perselisihan dalam mendapatkan otoritas publik terbuka secara lebar. Eickelman dan Anderson dalam hal ini menempatkan kelompok Muslim sebagai sebuah kelas kepentingan yang membawa bahasa dan tujuan Islam menuju otoritas publik.

Keterbukaan media memberikan akses kepada siapa saja untuk berkontribusi dalam menyebarkan nilai maupun simbol Islam ke ruang publik. Salah satuya yang tidak bisa dihindari adalah masuknya simbol Islam ke dalam budaya populer sebagai bagian dari daily life masyarakat kelas menengah. Seperti yang dikatakan oleh Heryanto (2011) bahwa dua dekade setelah tahun 1980-an, Islam berada di garis terdepan dalam memproduksi dan mengonsumsi budaya populer. Film Ayat-Ayat Cinta 2008 misalnya, menjadi pelopor film yang mempertontonkan simbol dan nilai Islam ke dalam sebuah cerita. Di tahun-tahun sebelumnya gejala ini memang sudah mulai terlihat, salah satunya tergambar dari karya-karya Rhoma Irama. Namun, Film Ayat-Ayat Cinta menjadi titik awal ketenaran dan mulai lakunya simbol Islam yang dipadu-padankan dengan budaya modern.

Heryanto (2015) mendefinisikan budaya populer dalam dua pengertian yang pada akhirnya saling berdampingan dan cenderung tidak bisa terpisahkan. Pertama, budaya populer akan dimaknai sebagai suara, gambar, dan pesan yang diproduksi secara masal dan komersial 
serta praktik pemaknaan terkait, yang berupaya menjangkau sebanyak mungkin konsumen Dalam hal ini budaya populer sebagai suatu komoditas yang di hasilkan oleh aktivitas industrial. Kedua, budaya populer yang dihasilkan dari proses komunikasi masyarakat sebagai alternatif dari budaya yang dihasilkan oleh proses industrial. Dalam konteks ini budaya populer lebih menekankan pada budaya yang diciptakan oleh masyarakat sendiri seperti perayaan, forum, peristiwa seperti acara festival, pesta rakyat, parade masuk di dalamnya. Secara sederhana, budaya populer dimaknai sebagai produk (film, musik, busana, novel, acara televisi, dan lainnya) yang mudah diakses dan dikonsumsi oleh masyarakat. Oleh karena itu, budaya populer sangat bersingungan dengan daily life, leisure time, entertainment dan life-style seseorang (Hall 1977).

Film Ayat-Ayat Cinta sendiri diadopsi dari sebuah novel karya Habiburrahman El Shirazy yang telah terbit empat tahun sebelum penayangan filmnya. Hal ini menunjukkan bahwa dunia sastra terutama novel juga ikut dalam proses ini. Novel sebagai sebuah bentuk budaya populer dengan simbol maupun nilai Islam sebagai latar belakang cerita utama serta nilainilai modern menjadi penyokongnya. Realitas inilah yang merupakan bagian dari Muslim publik di mana Islam mulai muncul di ruangruang publik dan menyatu dan/atau menjadi bagian dari alur cerita novel.

Begitu juga dengan Asma Nadia yang menjadi salah satu novelist yang gencar memproduksi novel-novel dengan memadupadankan nilai-nilai Islam dan problematika kehidupan perkotaan di alur ceritanya. Sejak awal kariernya sebagai novelis, Asma Nadia selalu komitmen dalam mengusung nilai dan simbol Islam di setiap alur cerita yang ia buat. Asosiasinya pada Forum Lingkar Pena memberikan 'sinyal' bahwa setiap karya yang dibuatnya mengandung semangat dakwah (Arnez 2009). Ini mengapa, meskipun dengan tema beragam seperti tentang rumah tangga, keluarga, percintaan remaja, hingga kisah petualangan perempuan, Asma selalu menyelipkan bahasa dan ajaran Islam di dalamnya.

\section{"Lincah dan Shalihah": Menjadi Sosok Jilbab Traveler}

Stuart Hall (1997) alam circuit of culture secara jelas mengaitkan representasi dengan terbentuknya identitas. Representasi sebagai proses produksi makna dengan membangun satu set korespondensi antara hal-hal yang menyangkut benda, orang, peristiwa, tanda, dan konsep. Makna-makna inilah yang akan membangun dan mengon-struksikan sebuah identitas yang bersifat kultural.

Melalui teksnya, Asma Nadia membangun karakter sosok "jilbab traveler" sebagai seorang yang "lincah" dan "shalihah". Dua sifat inilah yang merepresentasikan siapa, mengapa, dan bagaimana negosiasi seorang "jilbab traveler" dalam merespon apa yang Heryanto (2015) sebut sebagai "kemodernan" namun tetap pada koridor keislaman. Ini juga bagian dari proses bagaimana Asma Nadia membentuk-becoming and being- sosok "jilbab traveler" sebagai gambaran dari "Muslimah modern" melalui karyanya.

Sifat lincah dan shalihah tercemin dari penamaan "jilbab traveler" itu sendiri. Dengan menempatkan kata jilbab dengan traveler, Asma 
Nadia tidak hanya membangun citra penjelajah yang gemar berpindah dari satu tempat ke tempat menarik lainnya (mobility), namun juga sosok perempuan yang taat dan patuh dengan agamanya. Dalam konteks masyarakat Muslim, jilbab dianggap sebagai simbol utama dari gambaran ketaatan/kesalehan perempuan dalam berpakaian (Guindi 1999; Jones 2010; Pamungkas 2015).

Asma Nadia memperjelas karakter lincah pada sosok "jilbab traveler" melalui dua hal yang tergambarkan melalui dialog para tokoh. Pertama, melalui atribut yang dipakai oleh sosok "jilbab traveler". Penggambaran sosok dengan sepatu sneakers dan pakaian kasual tersebut menunjukkan bahwa Asma Nadia ingin mengonstruksikan si tokoh sebagai sosok yang lincah. Dengan asusmsi bahwa atribut-atribut tersebut memudahkan langkah dan gerak (mobility) si tokoh.

"Sepatu sneakers Rania terus melangkah....." (Nadia 2015:36)

"Syukurlah, sebelum keberangkatan gaya busana Rania yang kasual mendapatkan bantuan. Tia memperkenalkan dengan Moshaict ....... Tidak mengganggu gerak termasuk ketika berwudhu saat waktu sholat tiba." (Nadia 2015:153)

Kedua, melalui aktivitas-aktivitas yang dilakukan oleh si tokoh. Baik novel Jilbab Traveler: Love Sparks in Korea, Assalamualaikum Beijing, maupun buku The Jilbab Traveler sangat jelas menggambarkan perempuan-perempuan dengan mobilitas yang tinggi. Sosok Rania misalnya, tokoh tersebut digambarkan sebagai gadis yang telah menjelajahi 60 negara dan 288 kota di dunia. Hal ini juga diperjelas dengan teksteks yang mengarahkan bahwa si tokoh tersebut selalu ingin melangkah menjelajahi dunia - Rania ingin berjalan sejauh mungkin hingga bisa melihat bumi-Nya lebih luas (Jilbab Traveler: Love Sparks in Korea: 32).

Sedangkan, penggambaran shali-hah tidak hanya tercermin pada penempatan jilbab pada "jilbab traveler" - yang menjadi pembeda (sense of different), Asma Nadia juga menyertakan aturan-aturan agama yang melekat dan kuat dikonstruksikan pada perempuan Muslim.

"Asma merespons dengan senyum sambil mendekapkan tangan di depan dada." (Nadia 2014:12)

"Tidak ada ruang untuk melakukan kontak fisik dengan lawan jenis, termasuk berduaduaan di tempat sunyi." (Nadia 2015:178)

"Ketika gadis itu mengatakan hanya makan di restoran halal, tak jauh dari penginapan, Hyun Geun mengangguk tanpa berpikir panjang." (Nadia 2015:90)

"Supaya waktu shalat aman, rencanakan perjalanan." (Nadia 2012:318)

Dalam kutipan teks di atas menunjukkan bahwa sosok "jilbab traveler" adalah perempuan yang mampu menjaga perintah dan larangan agama dengan tetap menjaga sholat, menjaga kehalalan makanan, serta tidak bersentuhan dengan lawan jenis. Bagaimapun juga karakter tersebut menjadi penting yang akan membedakan "jilbab traveler" dengan traveler pada umumnya. Di sisi yang lain, karakter shalihah adalah jembatan untuk menegosiasikan wacana mobility dan 'kesucian' perempuan yang dikonstruksikan melalui larang dan batasan di ruang publik. Dalam teks Alquran (Surat AlAhzab ayat 33) maupun beberapa Hadis menjelaskan bahwa perempuan selayaknya tidak keluar rumah. Hal ini juga seolah sudah menjadi bagian dari budaya masyarakat Muslim. 
Moghadam (1993) menyebutkan bahwa perempuan dalam konteks masyarakat Muslim tidak mendapatkan posisi yang strategik baik secara legal maupun sosial. Perempuan melekat dengan konotasi domestik, rumah, dan ranah privat - di mana konstruksi ini khas mengakar dalam masyarakat patriarki. Melalui konsep "jilbab traveler" ini, Asma Nadia mencoba untuk memberikan "jalan tengah" bagaimana perempuan mampu keluar dari konstruksi tersebut. Namun, ini tidak didapatkan dengan begitu saja, batasan dan aturan diterapkan sebagai bentuk negosiasi. Seperti yang ditunjukkan dalam Gambar 1, di mana "jalan tengah" adalah bagaimana sebuah perjalanan seorang perempuan itu mendekatkan dan bukan menjauhkan diri dari Allah.

Dalam teks tersebut menunjukkan bahwa di setiap perjalanan seorang "jilbab traveler" tidak boleh meninggalkan kewajiban sebagai seorang Muslimah. Mereka tetap menjaga keimanan (piety), kesucian (sanscity), dan kesopanan (modesty) diri sebagai sosok perempuan sekaligus seorang Muslim yang Pamungkas (2015) sebut sebagai karakter Muslimah Modern.

Dalam konteks "jilbab traveler", piety (kesalehan) mengacu hal-hal yang diperintah dan dilarangan oleh Allah. Ini berarti bahwa Asma Nadia tetap mem-pertahankan ketakwaan dalam setiap perjalannya. Ketakwaan sendiri berasal dari kata takwa yang berarti terpeliharanya diri untuk tetap taat melak-sanakan perintah Allah dan menjauhi segara laranganNya. Dalam teksnya setidaknya terdapat sekitar 23 dialog yang menunjukkan bahwa makanan halal dan sholat adalah persoalan krusial. Selain itu, meskipun mempunyai mobilisasi tinggi, "jilbab traveler" digambarkan sebagai sosok yang tidak pernah me-ninggalkan sholat.

Sedangkan, sanctity (kesucian diri) digambarkan sebagai proses menjaga diri dengan tidak bersentuhan dengan lawan jenis. Bagi Asma yang tergambar dalam teksnya, menunjukkan bahwa sentuhan dengan lawan jenis (bukan mahram) adalah hal yang harus tetap terjaga dalam setiap perjalanan. Hal ini sangat di-tekankan oleh Asma Nadia, dengan menuliskan setidaknya 10 dialog yang menggambarkan larangan bersentuhan fisik dengan lawan jenis.

Selain itu, Asma juga sangat menekankan pada penggunaan pakaian yang tertutup dengan jilbab menutupi hingga dada. Ini mencerminkan konsep modesty (kesopanan) yang melekat pada sosok "jilbab traveler". Dalam teksnya, Asma juga menganggap bahwa memandang laki-laki termasuk perilaku yang tidak baik. Hal ini direpresentasikan salah satunya dari kata "pamali" yang diletakkan pada kalimat di bawah ini.

"Rania segera berpaling agar tak terpesona pada penampilan bad boy di depannya. Akhwat, Muslimah, jilbaber, pamali memandangi cowok lama-lama!" (Nadia 2015:169)

Pamali sendiri berarti larangan atau yang dianggap tabu dalam masyarakat. Dalam konteks ini Asma Nadia menunjukkan bahwa seorang "jilbab traveler" seharusnya bisa menjaga pandangan dari lawan jenis. Tidak hanya itu, Asma juga menekankan pada adab mempercantik diri dalam Islam. Di mana hal-hal yang mendatangkan rasa sakit dengan tujuan untuk mempercantik diri adalah perbuatan buruk bahkan diharamkan dalam Islam. 


\section{Ummu Battutah: "Si Gadis Lincah Penjelajah Dunia?"}

“'But you really are Ummu Battutah for me'. Seorang lelaki setengah baya keturunan Inggris dan Aljazair, melontarkan kalimat itu tiga tahun lalu" (Nadia 2015:153).

Salah satu tanda bahwa Asma Nadia hendak menggambarkan "jilbab traveler" sebagai gadis lincah adalah julukan "Ummu Battutah". Nama Ummu Battutah diambil dari nama Ibnu Battutah seorang penjelajah Muslim yang berasal dari Tangier, Maroko. Ibnu menunjukkan nama untuk laki-laki, sehingga Asma menggantinya menjadi Ummu yang mengarah pada sosok perempuan. Ibnu Battutah bernama lengkap Abu Abdullah Muhammad bin Battutah adalah sosok penjelajah dunia yang cukup terkenal dalam sejarah Islam. Dengan keberaniannya, selama 30 tahun Ia telah mampu mengunjungi tiga benua mulai dari Afrika Utara, Afrika Barat, Eropa Selatan, Eropa Timur, Timur Tengah, India, Asia Tengah, Asia Tenggara, dan Cina (Ruslan 2009). Perjalanan tersebut diawali oleh niatnya untuk menunaikan ibadah haji ke Makkah dan berziarah ke makam Rasulullah (Nabi Muhammad) di Madinah. Niat tersebut membawanya pada per-jalanan panjang hingga namanya menjadi icon penjelajah Muslim yang hebat. Selain itu, perjalanannya juga menghasilkan berbagai catatan tentang geografi, politik, sejarah, alam, dan adat lokal setempat yang bermanfaat bagi generasi selanjutnya

Dengan menyandingkan "jilbab traveler" dengan Ibnu Battutah melalui julukan "Ummu Battutah", hal ini menggambarkan beberapa hal. Pertama, "jilbab traveler" digambar sebagai sosok -yang layaknya laki-laki- mampu menjelajahi dunia, sekalipun ia berjilbab. Seperti tagline yang tertulis jelas dalam buku The Jilbab Traveler, "Berjilbab bukan berarti kamu nggak bisa keliling dunia!". Di sini Asma Nadia menekankan bahwa jilbab bukan sebagai penghalang, justru adanya jilbab adalah "tiket" untuk bisa keliling dunia. Layaknya Ummu Battutah yang di-gambarkan oleh Asma Nadia melalui sosok Rania. Dengan jilbabnya si tokoh justru digambarkan lebih mempunyai "ke-istimewaan" dari lingkungan sekitar sehingga mampu mendapat banyak ke-sempatan untuk keliling dunia. Meskipun bumbu-bumbu cerita yang diangkat dari realitas diskriminasi masyarakat Muslim di lingkungan global juga menyertai alur ceritanya, namun Asma Nadia tetap memberikan ruang lebih luas pada deskripsi-deskripsi tentang keistimewaan Islam.

Kedua, sebuah upaya untuk menyetaraan antara peran perempuan dengan laki-laki. Setidaknya dengan menyandingkan "jilbab traveler" dengan sosok Ibnu Battutah adalah upaya Asma Nadia dalam menggambarkan bahwa perempuan bisa menjadi sosok hebat layaknya laki-laki. Asma Nadia juga menggambarkan dalam diri seorang "jilbab traveler" adalah sosok perempuan saleh yang mandiri. Perempuan yang bisa kemana saja tanpa dampingan sosok laki-laki. Hal ini menunjukkan bahwa "jilbab traveler" tidak bergantung pada peran laki-laki di sisinya.

Ketiga, perjalanan seorang "jilbab traveler" yang jauh dari kesia-siaan dan keduniawian. Ibnu Battutah adalah penjelajah yang berkontribusi membawa citra Islam dalam dunia ilmu pengetahuan. Hal ini juga yang hendak Asma Nadia konstruksikan melalui julukan Ummu Battutah. Di mana Asma Nadia mengkonstruksikan perjalanan "jilbab traveler" sebagai bagian 
dari misi agama. Ia menekankan bahwa travelling bagi "jilbab traveler" adalah dakwah, memperkuat iman, ketakwaan, dan pengalaman.

"Miris membaca buku-buku traveling yang menyebarkan paham kebebasan, padahal seharusnya setiap perjalanan mendekatkan kita kepada Allah" (Nadia 2012).

\section{Jilbab: Dari Identitas, Negosiasi, hingga Jebakan Patriarki}

Guindi (1999:3-8) dalam buku Veil: Modesty, Privacy, and Resistance mendeskripsikan jilbab dari berbagai perspektif, konteks, dan budaya di masyarakat. Jilbab di Timur Tengah dianggap sebagai elemen material dan ideologi yang terhubung secara komplek dalam veil-haremeunuchs-seclusion-polygamy. Set ini berlangsung sejak ribuan tahun silam dan menyebar di peradaban Persia, Mesopotamia, Yunani, dan Romawi Timur. Dalam invansi berturut-turut dari dinasti Achaemenes (penguasa Persia) hingga kekaisaran kuno Asia, akhirnya set tersebut menjadi praktik sosial biasa. Sedangkan dalam perspektif feminis, kompleksitas set tersebut merupakan bagian dari penindasan perempuan. Dalam tradisi feminis Barat (Western-ideology feminists) pemaknaan jilbab memang mengarah pada wacana patriarki, keterbelakangan, subordinasi, dan penindasan.

Di sisi yang lain, Guindi (1999) melihat bahwa jilbab juga merupakan bagian dari sebuah gerakan (the movement). Jilbab dalam hal ini memainkan peran secara simbolis dalam sebuah perjuangan. Di Mesir pada pertengahan 1970-an, misalnya, pakaian islami yang dikenakan oleh perempuan menggantikan pakaian sekuler modern dan merupakan bagian dari gerakan aktivis akar rumput. Situasi ini juga terjadi di Turki dimana pakaian (terutama jilbab) telah menjadi penanda "garis depan" dalam pertempuran yang muncul antara pendukung masyarakat Islam dan sekularis ekstrem.

Lalu bagaimana pemaknaan jilbab dalam "jilbab traveler"? Dalam teks-teksnya, Asma Nadia mengkonstruksikan bahwa tidak hanya sekadar sehelai kain, jilbab adalah sosok "pelindung" dari kejahatan-kejahatan yang mungkin terjadi saat traveling - seperti tatapan nakal dari lawan jenis.

"Ini yang disebut jilbab..." Rania menyentuh kain yang menutupi kepala, leher hingga memanjang ke bawah, "identitas bagi perempuan Islam atau Muslimah agar mereka mudah dikenal. Pelindung juga dari tatapan nakal yang tidak diinginkan" (Nadia 2015:189).

Sosok pelindung inilah yang bisa menggantikan ketidakhadiran "mahram" (yang sering dikonotasikan sebagai laki-laki) dalam setiap perjalanan seorang "jilbab traveler". Pada titik inilah pemaknaan jilbab menjadi sesuatu yang paradoks. Satu sisi Asma Nadia mencoba menghadirkan semangat "kesetaraan" perempuan melalui jilbab - bahwa jilbab bukan halangan perempuan untuk menaklukkan dunia, di sisi lain jilbab masih terpaut dengan bayang-bayang budaya dan nilai patriarki. Udasmoro (2014) mengatakan bahwa meskipun ke-beradaan para pengarang perempuan dalam dunia sastra mulai mendominasi pasca runtuhnya orde baru, banyak di antara mereka yang tidak dapat dipisahkan begitu saja dari hadirnya kons-truksi maskulin yang bersifat laten. Hal ini menggambarkan bahwa pengarang perempuan tidak lantas sepenuhnya bisa keluar dari konstruksikonstruksi maskulin yang dibangun oleh budaya patriarki. Cornell (2005) menyebutnya sebagai 
sebuah maskulinitas hegemonik yang telah melekat dalam masyarakat.

Tidak bisa dipungkiri bahwa wacana mobility pada perempuan yang dikonstruksikan oleh Asma Nadia melalui "jilbab traveler", tidak benar-benar keluar dari bayang-bayang budaya patriarki. Alih-alih dimaknai sebagai sebuah gerakan, "jilbab traveler" adalah kebutuhan bagaimana perempaun Muslim menikmati imajinasi kemodernan, namun tetap pada jalur dan koridor ke-Islaman. Ini membantu mereka untuk tetap menjadi bagian dari Muslim yang shalih tetapi juga mampu menikmati produk dan imaji dari modernitas. Kesopanan, kesucian, dan ketakwaan yang ditonjolkan adalah "frame" yang membingkai kemodernan pada koridor religious, bukan pada nilai-nilai sekular.

\section{Jilbab Traveler: Antara Iman dan Kebutuhan Zaman}

Gidden (1991:1) dalam buku "Modernity and Self-Identity" mengung-kapkan bahwa modernitas telah mengubah secara radikal tidak hanya pada level institusi, tetapi juga day-to-day dari kehidupan sosial dan mempengaruhi level paling personal dari pengalaman hidup seseorang. Melalui arus globalisasi sebagai salah satu produk dari modernitas, misalnya, membawa masyarakat pada realitas "world-wide ties" yang mengaburkan ruang dan waktu. Ini juga termasuk pada transformasi kebutuhan dan gaya hidup masyarakat yang semakin terjebak pada realitas-realitas semu.

Dalam teksnya Asma Nadia tidak hanya menghadirkan imajinasi dari "tuntutan globalisasi" melalui tagline keliling dunia, tetapi juga cerminan pola pikir modern dan gaya hidup yang lebih kekinian. Penggambaran tokoh yang diasosiasikan dengan brand-brand fashion, misalnya, memberikan kesan lebih modis dan trendy - di sisi lain juga menandakan asosiasinya pada produk kapitalisme.

Sementara jilbab-jilbab segi empat yang berbahan ringan juga digantung sesuai nuansa warna, sehingga mata cepat memilih. Koleksi busananya cenderung praktis dan sederhana. "Masih setia saja sama Dauky." Tia menunjuk label baju-baju Rania" (Nadia 2015:136).

Namun dalam konteks ini, alih-alih lebih mengimajinasikan hingar-bingar moder-nitas yang lebih dekat dengan urusan duniawi, simbol Islam yang membalut setiap teks dan nilai-nilai Islam yang diterapkan di setiap alurnya mampu mengubah yang sekuler menjadi -sedikit- lebih religious. Melalui konsep ini Asma Nadia mencoba untuk menegosiasi antara pemahaman agama terhadap tuntutan dan kebutuhan zaman.

Pembaca akan senantiasa dibawa pada imajinasi akan "modern", sebuah imajinasi tentang perempuan dengan karier sukses, mempunyai pengagum laki-laki tampan, dan mobilisasi yang tinggi. Namun, juga tetap pada balutan simbol dan nilai Islam di dalamnya. Simbol dan nilai Islam menjadi "modal" penting karena akan berperan dalam memenuhi imajinasi atas keyakinan dan kebenaran yang dianut. Sehingga imajinasi "ke-modern-an" yang diterapkan tidak mengarah pada hal-hal yang terasosiasikan pada nilai-nilai sekuler, tetapi tetap pada koridor dan radar keislaman.

Keadaan ini selanjutnya dikenal sebagai istilah Islam populer. Konsep Islam populer memang dimaknai secara beragam. Jati (2017) dalam bukunya "Politik Kelas Menengah Muslim 
Indonesia" mendefinisikan Islam populer dari dua sisi. Pertama, secara terminologi, Islam populer dimaknai sebagai bentuk pengaruh modernisasi terhadap nilai-nilai budaya Islam dalam masyarakat. Kedua, secara teologis, Islam populer menekankan pada fleksibilitas dalam memahami dan menerapkan ajaran Islam ke dalam kehidupan, namun tetap pada koridor "syar'i". Dalam pemahaman ini, Islam populer aktif melakukan negosiasi-negosiasi kecil agar tetap menjadi Islam (sebuah keyakinan yang dianggap benar) tapi juga tidak meninggalkan kesan modern (sebagai sebuah kebutuhan zaman). Dua unsur (faith and needs) inilah yang melahirkan konsep Islam populer di dalam masyarakat.
Di sisi lain, Islam populer juga sebagai sebuah bentuk oposisi dari Islam ortodoks yang semala ini dikuasasi oleh elite keagamaan (Gaffney 1992 dalam Weintraub 2011). Dalam hal ini, Islam populer mampu menerobos batas-batas "sakral" menjadi sebuah selebrasi bersama dan menyatu di setiap gaya hidup masyarakat. Selain itu, Islam populer juga berkaitan dengan tradisi Sufisme yang menyebar di kawasan Asia Tenggara (Bowel, 1993; Geertz, 1968; Howell, 2001 dalam Weintraub 2011: 3; Woodward, 1989). Di mana tradisi Sufisme yang tersebar di kawasan Asia Tenggara cenderung disesuaikan dengan budaya lokal. Misalnya, hukum lokal, kepercayaan Hindu-Budha, dan praktik-praktik mistik yang mana telah terpatri sebelum Islam menyebar di kawasan tersebut.

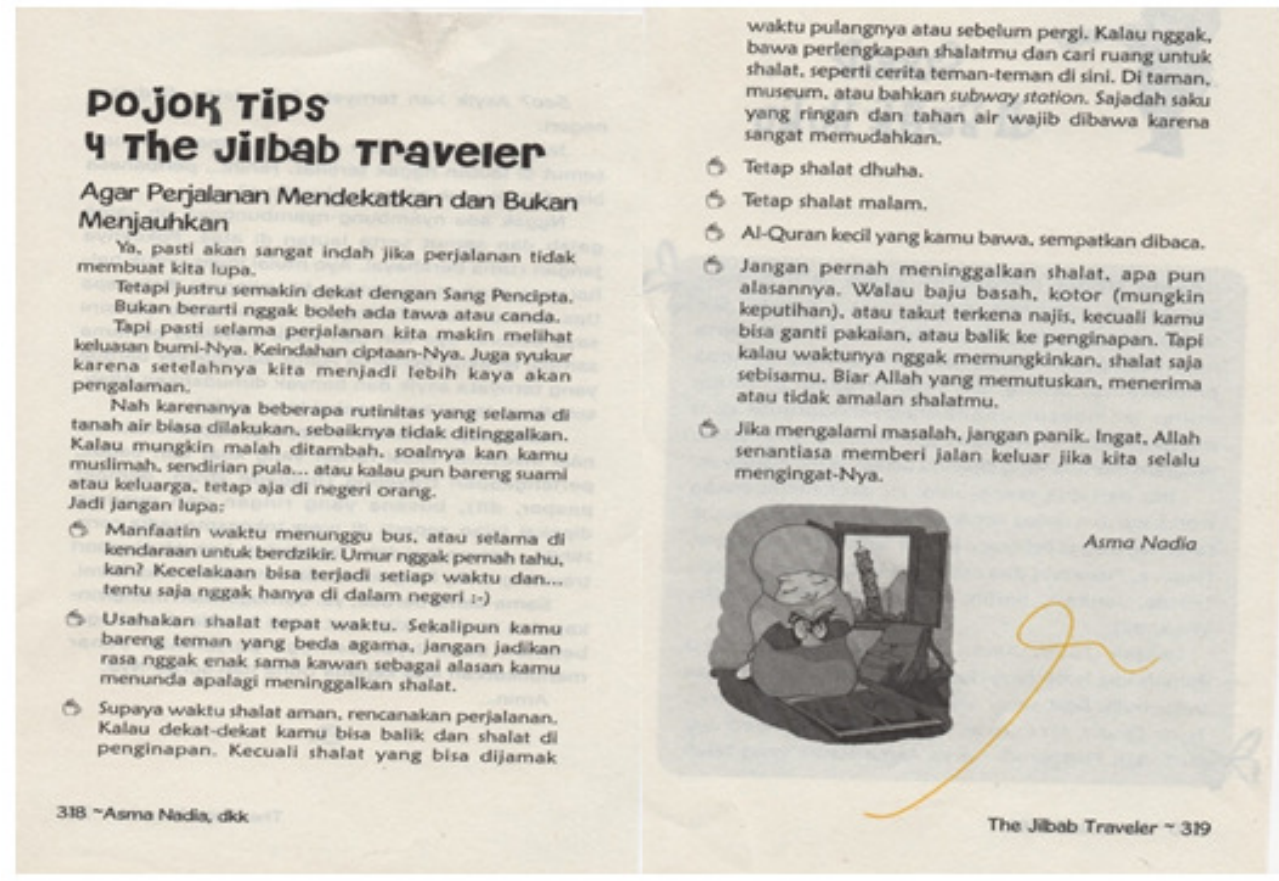

Gambar 1.

Pojok Tips "Agar Perjalanan Mendekatkan dan Bukan Menjauhkan", yang diberikan oleh Asma Nadia (Nadia 2012:318). 
Wacana Jilbab Traveler adalah salah satu potret dimana nilai-nilai Islam menyatu dalam kebutuhan gaya hidup masyarakat modern. Ini adalah upaya untuk menyeimbangkan keimanan dengan kebutuhan zaman. Hal inilah yang diterapkan oleh Asma Nadia dalam karyakaryanya yang tetap menonjolkan sisi islami dalam setiap alur ceritanya, namun juga tidak lupa dibalut dengan unsur-unsur modern di dalamnya. Ini memungkinkan para pembaca tidak hanya larut dalam nuansa "kenikmatan duniawi", tetapi juga tetap tenggelam dalam "kedamaian" yang diciptakan dari simbol dan nilai Islam yang menyertai setiap teks dari karya-karya Asma Nadia.

\section{Kesimpulan}

Kehadiran sosok Rania maupun Asmara dalam karya Asma Nadia berhasil menambah referensi dari wajah baru muslimah modern Melalui tiga karyanya, Asma Nadia menggambarkan sosok jilbab traveler sebagai perempuan yang lincah namun juga shalihah. Lincah mencer-minkan perempuan dengan mobilitas tinggi, mampu beradaptasi dan berpindah dari satu tempat ke tempat menarik lainnya. Sedangkan shalihah adalah cerminan ke-Islaman yang harus diton-jolkan, bukan hanya sebagai pembeda, namun juga sebagai ruang negosiasi. Asma Nadia mencoba membangun jalan tengah, di mana alih-laih dekat dengan nilai-nilai sekuler, kemodernan tetap dibungkus dengan keislaman yang utuh dengan tetap menjaga kesopanan, ketakwaan, dan kesucian diri.

Meskipun nampak sifat "eman-sipasi" dalam sosok jilbab traveler - dengan imajinasi mobilitasnya, Asma Nadia masih terjebak pada bayang-bayang budaya patiarki dengan menempatkan jilbab sebagai pengganti sosok pelindung (mahram). Ini menjelaskan bahwa hege-moni maskulinitas dari budaya patriarki masih melekat dalam wacana jilbab traveler. Alih-alih sebagai sebuah gerakan, jilbab traveler adalah kebutuhan bagai-mana perempuan muslim menikmati dan mengimajinasikan kemodernan, namun tetap pada koridor keislaman.]

\section{Daftar Pustaka}

Anderson, Jon W., dan Dale F. Eickelman. 1999. New Media in the Muslim World: The Emerging Public Sphere. Indianapolis: Indiana University Press.

Arnez, Monica. 2009. "Dakwah by Pen”. Indonesia and Malay World, 37 (107): 45-64.

Angkasa, Gaudensio. 2012. "Teori Postkolonial dalam Konteks Identitas." Academia.Edu. Retrieved July 26, 2020 (https://www. academia.edu/13233569/Teori_Postkolo nial_Dalam_Konteks_Identitas).

Barker, Chris. 2016. Cultural Studies Teori dan Praktik. Yogyakarta: Kreasi Wacana.

Barkin, Gareth. 2014. "Commercial Islam in Indonesia: How Television Producers Mediate Religiosity among National Audiences." International Journal of Asian Studies 11(1):1-24.

Connell, R. W. 2005. Masculinities. 2nd ed. Calif: University of California Press.

Guindi, El Fadwa. 1999. Veil: Modesty, Privacy, and Resistance. New York: Oxford International Publishers Ltd. 
Gramsci, Antonio. 1975. Prison Notebooks. The United States: Colombia University Press.

Gramsci, Antonio. 1971. Selections from Prison Notebooks of Antonio Gramsci. New York: International Publishers.

Hall, Stuart. 1992. Modernity an Introduction to Modern Societies. Ed. S. Hall. London: Blackwell Publishers.

Hall, Stuart. 1997. Representation Cultural Representations and Signifying Practices. London: SAGE Publications Ltd.

Heryanto, Ariel. 2011. "Upgraded Piety and Pleasure: The New Middle Class and Islam in Indonesian Popular Culture." pp. 60-82, dalam A. N. Weintraub (ed.), Islam and Popular Culture in Indonesia and Malaysia, London: Routledge.

Heryanto, Ariel. 2015. Identitas dan Kenikmatan: Politik Budaya Layar Indonesia. Jakarta: Kepustakaan Populer Gramedia.

Huq, Maimuna. 1999. From Piety to Romance: Islam-Oriented Texts in Bangladesh. Indianapolis: Indiana University Press.

Jati, Wasito Raharjo. 2017. Politik Kelas Menengah Muslim Indonesia. Depok: LP3ES.

Jones, Carla. 2010. "Images of Desire: Creating Virtue and Value in an Indonesian Islamic Lifestyle Magazine." Journal of Middle East Women's Studies 6(3):91-117.

Lasman, Diah. 2010. "Representasi Anak Muda Prancis dalam Lirik Lagu Rap Karya Rohff." Depok.

Moghadam, Valentine M. 1993. Modernizing Women: Gender and Social Change in the Middle East (Women and Change in the Developing World). Amerika Serikat: Lynne Rienner Publishers.
Nadia, Asma. 2012. The Jilbab Traveler. Jakarta: Asma Nadia Publishing House.

Nadia, Asma. 2014. Assalamualaikum Beijing. Jakarta: Asma Nadia Publishing House.

Nadia, Asma. 2015. Jilbab Traveler: Love Spark in Korea. Jakarta: Asma Nadia Publishing House.

Nilan, Pam, dan Michelle Mansfield. 2013. "Youth Culture and Islam in Indonesia." Wacana, Journal of the Humanities of Indonesia 15(1):1.

Pamungkas, Arie Setyaningrum. 2015. "The Dakwah Media in Post Suharto Indonesia: From Politics of Identity to Popular Culture (The Case of Ummi)." Universität Zu Berlin, Berlin.

Piliang, Y. A. 2004. "Semiotika Teks: Sebuah Pendekatan Analisis Teks". Mediator 5 (2), 169-198

Shafita, Maria. 2009. "Wacana Tentang Wacana dalam Media Massa: Tren, Identitas, dan Komoditas." Universitas Indonesia, Depok.

Smith-Hefner, Nancy J. 2007. "Javanese Women and the Veil in Post-Soeharto Indonesia." Journal of Asian Studies 66(2):389-420.

Utomo, Ariane, Anna Reimondos, Peter McDonald, Iwu Utomo, and Terence Hull. 2018. "Who Wears the Hijab? Predictors of Veiling in Greater Jakarta." Review of Religious Research 60(4):477-501.

Udasmoro, Wening. 2017. "Reproduksi Womenhood dalam Novel Bunda: Kisah Cinta 2 Kodi Karya Asma Nadia". Adabiyyat: Jurnal Bahasa dan Sastra, Vol 1 (2), 182-200

Weintraub, Andrew. 2011. Islam and Popular Culture in Indonesia and Malaysia. London: Routledge 
This page was intentionally left blank. 